\title{
Patient-reported QoL in anal cancer survivors 3 and 6 years after treatment-results from the Swedish national ANCA study
}

\author{
Anna Axelsson ${ }^{1,2} \cdot$ Mia Johansson ${ }^{2,3} \cdot$ David Bock $^{1} \cdot$ Eva Haglind $^{1}$ (D) Hanna de la Croix ${ }^{1,4} \cdot$ Per J. Nilsson $^{5}$. \\ Eva Angenete $e^{1,4}$
}

Received: 19 May 2021 / Accepted: 16 December 2021 / Published online: 26 January 2022

(c) The Author(s) 2022

\begin{abstract}
Purpose The impact of anal cancer treatment for the patients is best evaluated by the patients themselves. The purpose of this study was to investigate quality of life (QoL) in patients with anal cancer at 3 and 6 years after treatment.

Methods A Swedish national cross-sectional prospective cohort study with patients diagnosed with anal cancer between 2011 and 2013. Patients were invited to respond to a QoL questionnaire at 3 and 6 years, with focus on bowel, urinary and sexual function, social and mental function, co-morbidity, lifestyle, daily activities, personal characteristics, and perceived QoL. It also contained questions on the severity of the symptoms regarding occurrence, frequency, and duration and the level of "bother" experienced related to functional symptoms.

QoL and prevalence of bother with urinary, sexual, bowel dysfunction, and anal pain were described. The prevalence of impaired QoL was compared with a healthy reference population. The association between QoL and experiencing bother was quantified by regression models.

Results From an original cohort of 464 patients with anal cancer, 264 (57\%) were alive and contacted at 3 years and 230 $(50 \%)$ at 6 years. One hundred ninety-five (74\%) patients responded to the 3-year and $152(66 \%)$ to the 6-year questionnaire. Sixty percent reported low QoL at both 3 and 6 years. Impaired QoL was more prevalent among patients with major bother due to bowel dysfunction (at 3 years RR 1.42, 95\% CI (1.06-1.9) p-value 0.020, at 6 years RR 1.52, 95\% CI (1.03-2.24) $p$-value 0.034 ) and urinary dysfunction (at 6 years RR $1.44,95 \%$ CI (1.08-1.91) $p$-value 0.013 ). There was a tendency to a positive relationship between the number of bodily functions causing bother and risk for impaired QoL.

Conclusion Patients treated for anal cancer reported bother regarding several bodily functions as well as poor QoL both at 3 and 6 years without much improvement. Bother was also associated with low QoL indicating that function-related bother should be addressed.
\end{abstract}

Keywords Anal cancer $\cdot$ Late side-effects $\cdot$ Survivorship $\cdot$ QoL $\cdot$ Bother of functional symptoms

Anna Axelsson

anna.c.axelsson@gu.se

1 Department of Surgery, SSORG-Scandinavian Surgical Outcomes Research Group, Institute of Clinical Sciences, Sahlgrenska Academy, University of Gothenburg, Gothenburg 416 85, Sweden

2 Department of Oncology, Region Västra Götaland, Sahlgrenska University Hospital/Sahlgrenska, 41345 Gothenburg, Sweden
3 Department of Oncology, Institute of Clinical Sciences, Sahlgrenska Academy, University of Gothenburg, Gothenburg, Sweden

4 Department of Surgery, Region Västra Götaland, Sahlgrenska University Hospital/Östra, Gothenburg, Sweden

5 Department of Surgery, Div. of Coloproctology, Karolinska University Hospital, Stockholm, Sweden 


\section{Introduction}

Treatment for anal cancer has improved immensely over the past decades with combined chemoradiation now being the primary therapeutic option and surgery mainly reserved for patients with incomplete response or recurrence $[8,15]$. In recent trials of different treatment regimens, 5-year survival rates of approximately $80 \%$ are reported [13]. The high curation rates lead to a sizeable cohort of anal cancer survivors and, thus, the concept of survivorship, i.e., living with longterm side effects related to the received treatment [1, 19] becomes increasingly important.

Radiotherapy causes structural changes in exposed organs i.e., bowel, anal sphincter, genital organs, and bladder. It may affect bowel, urinary and sexual function and can also lead to impaired musculoskeletal function and mobility [6, $14,24,28]$. The radiation dose and the irradiated volume are important factors influencing adverse late side effects but individual factors such as genetic susceptibility and smoking are also believed to be of importance $[1,16]$. Symptoms and impairment of function may have an impact on the patient's quality of life (QoL), but to what extent can only fully be estimated through the patient's own assessment [1, 19]. As side effects caused by radiotherapy can be progressive and develop years after exposure long-term follow-up is of importance, or the burden of symptoms experienced by anal cancer survivors may be underestimated [19]. Previous studies on QoL in patients with anal cancer and long-term follow-up were presented in a review performed by Sodergren et al. describing 11 studies using mainly EORTC QoL questionnaire (EORTC QLQC-30 or EORTC QLQCR-29). Results from these studies showed that bowel problems with diarrhea and impaired sexual function were the most common areas affecting QoL, and conclusion from the review was that there was a need for QoL questionnaire more specific for patients with anal cancer in future studies [19]. This has now been put into place, and there is a new EORTC questionnaire for patients treated for anal cancer (EORTCANL27) [18].

Our hypothesis was that there was a deterioration in QoL between 3 and 6 years of follow-up indicating a need for a long-term follow-up. We also hypothesized that low QoL correlated to one or more impaired body functions, as has been seen in previously in patients treated for rectal and prostate cancer [26, 27]. The aim of this study was to describe patient-reported QoL and bother due to dysfunction in bodily functions in patients treated for anal cancer at 3 and 6 years after conclusion of treatment and to study the relationship between QoL and bother [19].

\section{Material and methods}

\section{Study design}

The ANal CAncer study (ANCA) is a national crosssectional study regarding QoL and functional outcome in patients with anal cancer. The study is based on a Swedish national cohort of patients diagnosed with anal cancer between January 2011 and December 2013 identified through the Swedish Cancer Register at the Swedish National Board of Health and Welfare.

\section{Data collection}

Following patient approval, clinical data was collected from the Patient register at the Swedish National Board of Health and Welfare and from patient charts, collected from Swedish hospitals, using a standardized procedure with pre-specified clinical record form (CRF). Only patients with invasive squamous cell carcinoma of the anus were included in the study and invited to respond to a study-specific questionnaire at 3 and 6 years after diagnosis. The questionnaire was constructed according to a well-established method described elsewhere [21]. At the time when the study was designed, there was no pre-existing anal specific QoL instrument in use and for example, EORTC QLQ-C30 was considered to be too unspecific to answer our research question, and therefore, the decision was made to construct a more suitable questionnaire. The questionnaire included in total 260 questions with focus on bowel, urinary and sexual function, social and mental function, co-morbidity, lifestyle, daily activities, personal characteristics, and perceived QoL. It also contained questions about the severity of symptoms of occurrence, frequency and duration, and about the level of bother experienced relating to function. The 29-item Sense of Coherence scale (SOC-29) was also included [3]. Not all questions and instruments were used in the analysis for this sub-study, since focus was on QoL, explanatory variables, and bother regarding functional outcomes.

\section{Administration of questionnaires}

Initially, all patients in the cohort received a letter with information concerning the study and an invitation to participate. A few days later, the patients were contacted by telephone from a research nurse to obtain consent to study inclusion and permission to send out the questionnaire. Two weeks after the questionnaire was sent, the patients received a postcard with a thank you note and a 
reminder if the questionnaire had not been returned. One final reminder by telephone was attempted after the initial contact. Previously, this procedure has achieved an overall response rate of approximately $90 \%[2,5,10]$.

\section{Outcome measures and possible explanatory variables}

The primary endpoint was patient-reported QoL at 3 and 6 years. This was assessed in the question "how would you describe your QoL in the past month?" The response categories were presented in a Likert scale from 0 to 6 with $0=$ no QoL and $6=$ the best possible QoL. The response options were then dichotomized as has been done previously (0-4 = low QoL and 5-6= good QoL) [21].

Potential explanatory variables for low QoL were selected both through clinical expertise and previously published results. Sense of coherence has previously been reported to impact on QoL in patients with rectal cancer and was therefore included [4]. Depression may affect QoL and was explored using the question: "would you call yourself depressed?" with response categories no, yes, or don't know. This question has previously been validated in relation to the Hospital Anxiety Depression Scale [17]. Functional impairment (bowel, urinary, sexual) and anal pain were all considered potential explanatory variables. Bother regarding functional impairments was evaluated using questions about the level of bother from symptoms. For example: "how would you feel if this last month's bowel impairment was to remain the same for the rest of your life?". Each bother question had five response categories: "Not relevant, I haven't had any bowel impairment the last month," "It wouldn't bother me at all," "It would bother me slightly," "It would bother me moderately," and "It would bother me very much."

The responses were grouped into three categories: no bother (no problems thus no bother), minor bother (no or slight bother), and major bother (moderate or much bother). Other factors included as potential explaining variables were self-reported comorbidity, socio-economic status, and type of treatment for anal cancer.

\section{Reference population}

For comparison, we used a reference population of 1078 Swedish persons who answered identical questions included in a questionnaire described elsewhere [7]. The reference cohort was randomly selected from the Swedish population through the Swedish Tax Agency and completed the questionnaire between 2014 and 2015. The reference population was born between 1924 and 1983 with a median age of 63 years on accrual and a female:male ratio of $53 \%: 47 \%$ [7].

\section{Statistical analysis}

The prevalence of low QoL in the study population was assessed by a generalized linear multi-level model with a logit link and Bernoulli distribution [23]. A random intercept was used to account for the intra-patient dependence of the longitudinal data. Gender and time were included as a fixed effect and age as a continuous covariate as well as two- and three-way interaction effects in order to allow for synergy effects. Individual random effect (conditional) predictions as well as least-square mean fixed effect (marginal) predictions with $95 \%$ confidence intervals (CI) were displayed graphically. The mean effects of age were evaluated at the first and third quantiles of age at inclusion, 58 and 71 years, respectively. The prevalence in the reference population was reported using crude rates with $95 \% \mathrm{CI}$. The relationship between bother and the prevalence of low QoL was evaluated by regression analysis using the modified Poisson regression approach of Zou [29] with both unadjusted and adjusted analyses (adjusted for gender, depression, meancentred age, and SOC-29). Results are presented separately for 3 and 6 years as risk ratio and 95\% CI. The ANCA and reference cohort were compared with regard to the prevalence of impaired QoL by means of odds ratios, 95\% confidence intervals, and $p$-values. The association between $\mathrm{QoL}$ and the number of dysfunctions (bowel, urinary and sexual) that gives rise to major bother (none, one, two, or three) was assessed using a logistic regression model with number, subgroup (3- and 6-year follow-up and reference population) and number subgroup as fixed effects and the same variables for adjustment as previously. Results were presented graphically by the estimated risks of impaired QoL and 95\% CI. Parameter estimation was done using the Glimmix and Genmod procedures in SAS version 9. (SAS Institute Inc., Cary, NC, USA) and graphics with ggplot in R version 3.6.3 [25].

\section{Results}

From an original cohort of 464 patients with anal cancer, 264 were alive and contacted at 3 years and 230 at 6 years. In total 195 patients (74\%) responded to the 3-year questionnaire and $152(66 \%)$ to the 6-year questionnaire (Fig. 1). Nine patients who declined participation at 3 years participated and responded at 6 years. In total, 204 unique patients responded to at least one questionnaire. In Table 1 demography, clinicopathological and treatment details are presented. More than $60 \%$ were current or previous smokers. Fortythree percent of patients had tumors with nodal involvement at diagnosis. The majority of patients received chemoradiotherapy with curative intention (Table 1).

Overall, $60 \%$ of patients with anal cancer reported low QoL at both 3 and 6 years with no tendency to change over 
Fig. 1 In total, 195 responded to the 3-year follow-up questionnaire and 152 to the 6-year follow-up questionnaire. Nine patients who declined participation at 3 years participated and responded at 6 years participated and responded at 6 years. In total, 204 unique patients responded to at least one questionnaire

time. In the reference population, low QoL was reported in $52 \%$ (Fig. 2), and this did not differ from the patient population. In Table 1, the potential explanatory variables sense of coherence, depression, and level of bother from functional impairment are presented. Both senses of coherence and depression appeared stable over time. The rate of depression was slightly higher among patients compared to the reference population, at 3 years with $19 \%$ and at 6 years with $17 \%$, compared to controls with $14 \%$. The reference population reported major bother from bowel $(13 \%)$, urinary $(13 \%)$, and sexual function $(18 \%)$. The patients reported a higher degree of bother regarding all functions (bowel $51 \%$, urinary $33 \%$, and sexual function $26 \%$ ). Although no statistical comparisons were made, it seems as if bother of urinary function remained high over time, whereas bother regarding anal pain, sexual function and bowel function seemed to decrease somewhat over time (Table 2).

Level of bother as an explanatory variable for low QoL was explored with regression analysis presented in Table 3 . Impaired QoL was more prevalent among patients with major bother due to bowel dysfunction (at 3 years RR 1.42, 95\% CI (1.06-1.9) $p$-value 0.020 , at 6 years RR 1.52, 95\% CI (1.03-2.24) $p$-value 0.034$)$ and urinary dysfunction (at 6 years RR 1.44, 95\% CI (1.08-1.91) $p$-value 0.013$)$. The correlation between numbers of bothers regarding impaired functions, and QoL is reported in Fig. 3. In the reference population, no obvious relationship between numbers of bother responses, and QoL was observed; whereas for patients, there was a tendency for a positive relationship between numbers of bodily functions causing bother and risk of impaired QoL for those reporting one and two bothers of functions. We only found patients reporting three bothers of function at 3 years and not at 6 years and with a decreasing tendency of relationship with QoL.

\section{Discussion}

Radiotherapy causes a continuous tissue damage that might increase over time and negatively affect body functions. Our hypothesis was that QoL would deteriorate between 3 and 6 years after diagnosis in patients treated for anal cancer. Although results from the investigated cohort may indicate a lower QoL following treatment for anal cancer compared to a reference population, deterioration over time could not be confirmed.

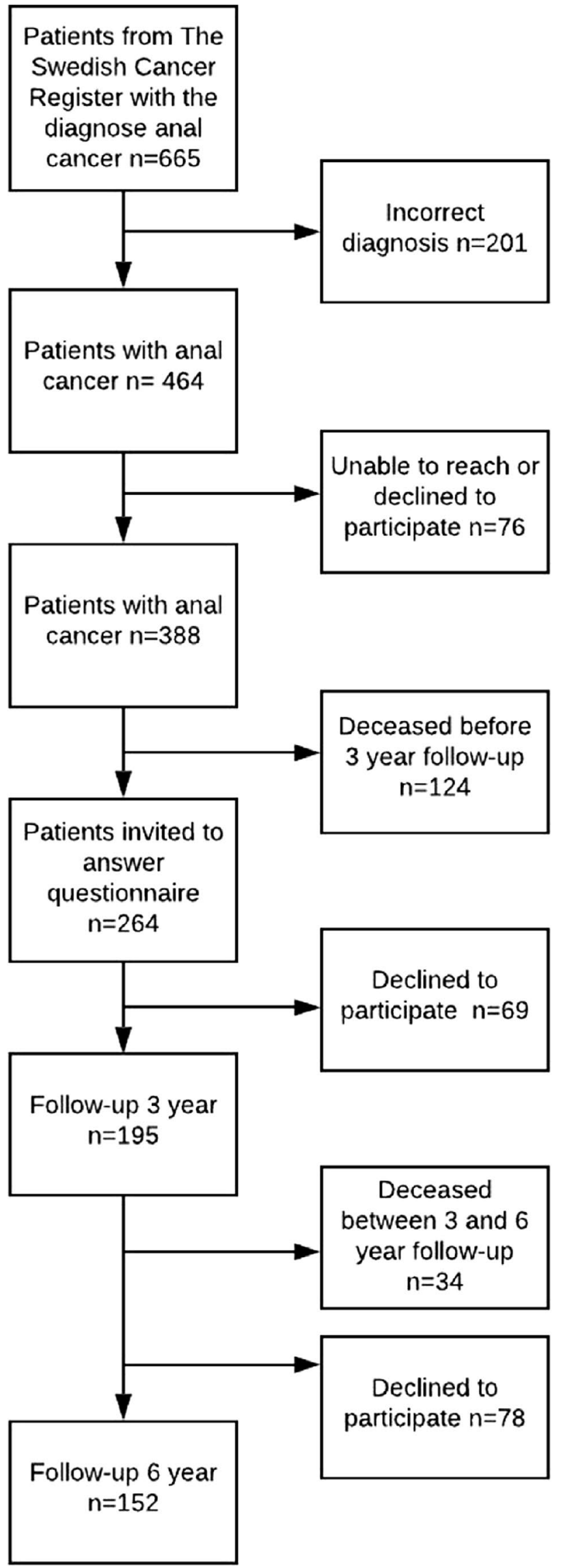


Table 1 Demography

\begin{tabular}{|c|c|}
\hline Variable & $\begin{array}{l}\text { Questionnaire } \\
\text { responders* } \\
(n=204)\end{array}$ \\
\hline Age (median) & 64 \\
\hline \multicolumn{2}{|l|}{ Gender } \\
\hline Male & $46(23 \%)$ \\
\hline Female & $158(78 \%)$ \\
\hline \multicolumn{2}{|l|}{ Marital status } \\
\hline In a relationship & $175(86 \%)$ \\
\hline Not in a relationship & $20(10 \%)$ \\
\hline Missing & $9(4 \%)$ \\
\hline \multicolumn{2}{|l|}{ Occupation } \\
\hline Working & $59(29 \%)$ \\
\hline Retired & $132(65 \%)$ \\
\hline Unemployed or student & $6(3 \%)$ \\
\hline Sick leave (full or part time) & $24(12 \%)$ \\
\hline \multicolumn{2}{|l|}{ Smoking } \\
\hline Current smoker & $31(15 \%)$ \\
\hline Previous smoker & $95(47 \%)$ \\
\hline Never smoker & $74(36 \%)$ \\
\hline Missing & $4(2 \%)$ \\
\hline \multicolumn{2}{|l|}{ Comorbidity } \\
\hline Diabetes & $14(7 \%)$ \\
\hline Hypertension & $58(28 \%)$ \\
\hline Cardiovascular disease & $26(13 \%)$ \\
\hline Cerebrovascular disease & $4(2 \%)$ \\
\hline Renal dysfunction & $2(1 \%)$ \\
\hline COPD/asthma & $11(5 \%)$ \\
\hline HIV-positive & $2(1 \%)$ \\
\hline Immunosuppression & $9(4 \%)$ \\
\hline \multicolumn{2}{|l|}{ Stoma } \\
\hline Yes & $49(24 \%)$ \\
\hline No & $146(72 \%)$ \\
\hline Missing & $9(4 \%)$ \\
\hline \multicolumn{2}{|l|}{ TNM staging (AJCC 7th edition) } \\
\hline 0 & $6(3 \%)$ \\
\hline I & $31(15 \%)$ \\
\hline II & $76(37 \%)$ \\
\hline III A & $31(15 \%)$ \\
\hline III B & $52(26 \%)$ \\
\hline IV & $3(2 \%)$ \\
\hline Missing & $5(3 \%)$ \\
\hline \multicolumn{2}{|l|}{ Initial treatment strategy ${ }^{1}$} \\
\hline Curative & $201(99 \%)$ \\
\hline Palliative & $0(0 \%)$ \\
\hline Missing & $3(2 \%)$ \\
\hline \multicolumn{2}{|l|}{ Type of primary treatment ${ }^{2}$} \\
\hline Chemoradiotherapy & $102(50 \%)$ \\
\hline Radiotherapy & $48(24 \%)$ \\
\hline Chemotherapy followed by radiotherapy & $39(19 \%)$ \\
\hline Chemotherapy & $1(1 \%)$ \\
\hline
\end{tabular}

Table 1 (continued)

\begin{tabular}{ll}
\hline Variable & $\begin{array}{l}\text { Questionnaire } \\
\text { responders* } \\
(n=204)\end{array}$ \\
\hline Surgery & $7(3 \%)$ \\
Surgery + adjuvant treatment & $2(1 \%)$ \\
Best supportive care & $5(2 \%)$ \\
Type of chemotherapy & $(n=144)$ \\
Mitomycin +5FU & $100(69 \%)$ \\
Platinum +5FU & $40(28 \%)$ \\
Other & $4(3 \%)$ \\
Radiotherapy total gray & $(n=192)$ \\
$<55$ Gray & $37(19 \%)$ \\
$55-60$ Gray & $82(43 \%)$ \\
$>60$ Gray & $73(38 \%)$ \\
\hline${ }^{1}$ Decision from multidisciplinary conference & \\
${ }^{2}$ Treatment received & \\
$*$ Participants who have responded to at least one questionnaire at 3- \\
or 6-year follow-up. (Three years $\mathrm{n}=195,6$ years $\mathrm{n}=152,9$ partici- \\
pants responded only at 6-year questionnaire)
\end{tabular}

However, patients experiencing bother from functional symptoms had lower QoL, and this correlation was more apparent for bowel and urinary function. Our findings were corroborated by those found in a Danish study where 21\% of patients reported great distress due to urinary dysfunction [24]. Additionally, we found indications that patients who experienced major bother with bowel function had a reduced QoL both at 3 and 6 years consistent over time. Bother with bowel function has been reported before in patients with anal cancer [19, 22, 24], but it is important to stress that there was no clear improvement over time. Our findings that anal pain had a tendency to cause major bother as well as low QoL, indicating that it is important to address this at follow-up.

We did not find any difference in QoL related to level of bother with sexual function. Previous studies have reported impaired sexual function as one of the most common problems, but perhaps bother of sexual function is not as important for overall QoL as previously thought [19]?

The results of the study confirmed our second hypothesis, that low QoL is correlated to one or more functional symptoms causing bother. This finding has not previously been reported in relation to patients with anal cancer. We also found that bother of some functions seemed to be more important than others. Similar research has been performed in the prostate cancer field with comparable results, and in one study bother relating to bowel and urinary function tended to become worse over time and in turn negatively affected QoL, while bother regarding sexual dysfunction was not perceived as equally severe, nor did it affect the QoL to the same extent [9]. It is possible that this is due to the imperative nature of a good bowel and urinary function. It 
Fig. 2 QoL Adjusted mean predictions for the risk of low QoL at 3 and 6 years in the ANCA cohort and in the reference population ("Reference"). The adjustment variable age is set at first and third quantiles of age at inclusion, 58 and 71 years, respectively. The figure demonstrates the individual and average risk of impaired quality of life with $95 \%$ confidence intervals. As benchmark, the corresponding risk in the reference group is displayed with 95\% CI

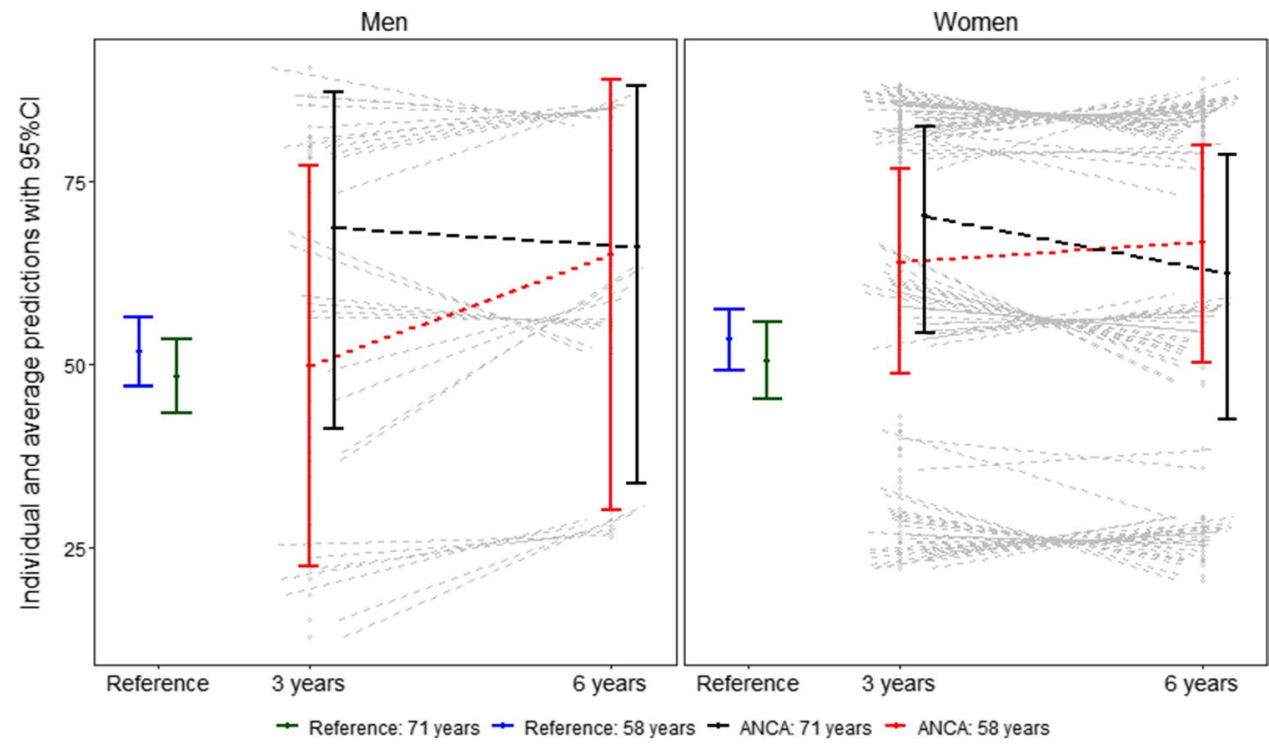

Table 2 Outcome variables-QoL, sense of coherence, depression, and bother

\begin{tabular}{|c|c|c|c|c|c|c|c|}
\hline Variable & Category & Reference $(n=1078)$ & $(\%)$ & 3 years $(n=195)$ & $(\%)$ & 6 Years $(n=152)$ & $(\%)$ \\
\hline \multirow[t]{3}{*}{ QoL } & Good & $511 / 1062$ & 48 & $76 / 188$ & 40 & $59 / 146$ & 40 \\
\hline & Low & $551 / 1062$ & 52 & $112 / 188$ & 60 & $87 / 146$ & 60 \\
\hline & Missing & $16 / 1078$ & 2 & $7 / 195$ & 4 & $6 / 152$ & 4 \\
\hline Sense of Coherence & Median (Q1;Q3) & $154(138 ; 167)$ & & $155(141 ; 167)$ & & $155(138.5 ; 169)$ & \\
\hline \multirow[t]{4}{*}{ Depressed } & No & $919 / 1068$ & 86 & $157 / 194$ & 81 & $126 / 151$ & 83 \\
\hline & Yes/don't know & $149 / 1068$ & 14 & $37 / 194$ & 19 & $25 / 151$ & 17 \\
\hline & Missing & $10 / 1078$ & 1 & $1 / 195$ & 1 & $1 / 152$ & 1 \\
\hline & $\mathrm{n}$ & 1066 & & 190 & & 148 & \\
\hline \multirow[t]{4}{*}{ Bother of bowel function } & No bother & $717 / 1060$ & 77 & $42 / 186$ & 23 & $39 / 148$ & 26 \\
\hline & Minor bother & $202 / 1060$ & 19 & $49 / 186$ & 26 & $44 / 148$ & 30 \\
\hline & Major bother & $141 / 1060$ & 13 & $95 / 186$ & 51 & $65 / 148$ & 44 \\
\hline & Missing & $18 / 1078$ & 2 & $9 / 195$ & 5 & $4 / 152$ & 3 \\
\hline \multirow[t]{4}{*}{ Bother of urinary function } & No bother & $735 / 1057$ & 70 & $84 / 193$ & 44 & $50 / 149$ & 34 \\
\hline & Minor bother & $188 / 1057$ & 18 & $46 / 193$ & 24 & $52 / 149$ & 35 \\
\hline & Major bother & $134 / 1057$ & 13 & $63 / 193$ & 33 & $47 / 149$ & 32 \\
\hline & Missing & $21 / 1078$ & 2 & $2 / 195$ & 1 & $3 / 152$ & 2 \\
\hline \multirow[t]{4}{*}{ Bother of sexual function } & No bother & $658 / 1038$ & 63 & $121 / 187$ & 65 & $107 / 148$ & 72 \\
\hline & Minor bother & $195 / 1038$ & 19 & $18 / 187$ & 10 & $15 / 148$ & 10 \\
\hline & Major bother & $185 / 1038$ & 18 & $48 / 187$ & 26 & $26 / 148$ & 18 \\
\hline & Missing & $40 / 1078$ & 4 & $8 / 195$ & 4 & $4 / 152$ & 3 \\
\hline \multirow[t]{4}{*}{ Bother of anal pain } & No bother & & & $125 / 189$ & 66 & $105 / 151$ & 70 \\
\hline & Minor bother & & & $28 / 189$ & 15 & $27 / 151$ & 18 \\
\hline & Major bother & & & $36 / 189$ & 19 & $19 / 151$ & 13 \\
\hline & Missing & $1078 / 1078$ & 100 & $6 / 195$ & 3 & $1 / 152$ & 1 \\
\hline
\end{tabular}

might be that disturbed bowel and urinary function impacts on social interaction and that this in turn causes bother, while the loss of ability to have sex, even though of great importance to many, may be more easily accepted.
This study is unique in the context of anal cancer as it relates to the bother patients perceive rather than the actual functional symptoms, giving the patients the prerogative to decide what they find important. One possible reason for no clear deterioration of QoL over time might be that the 


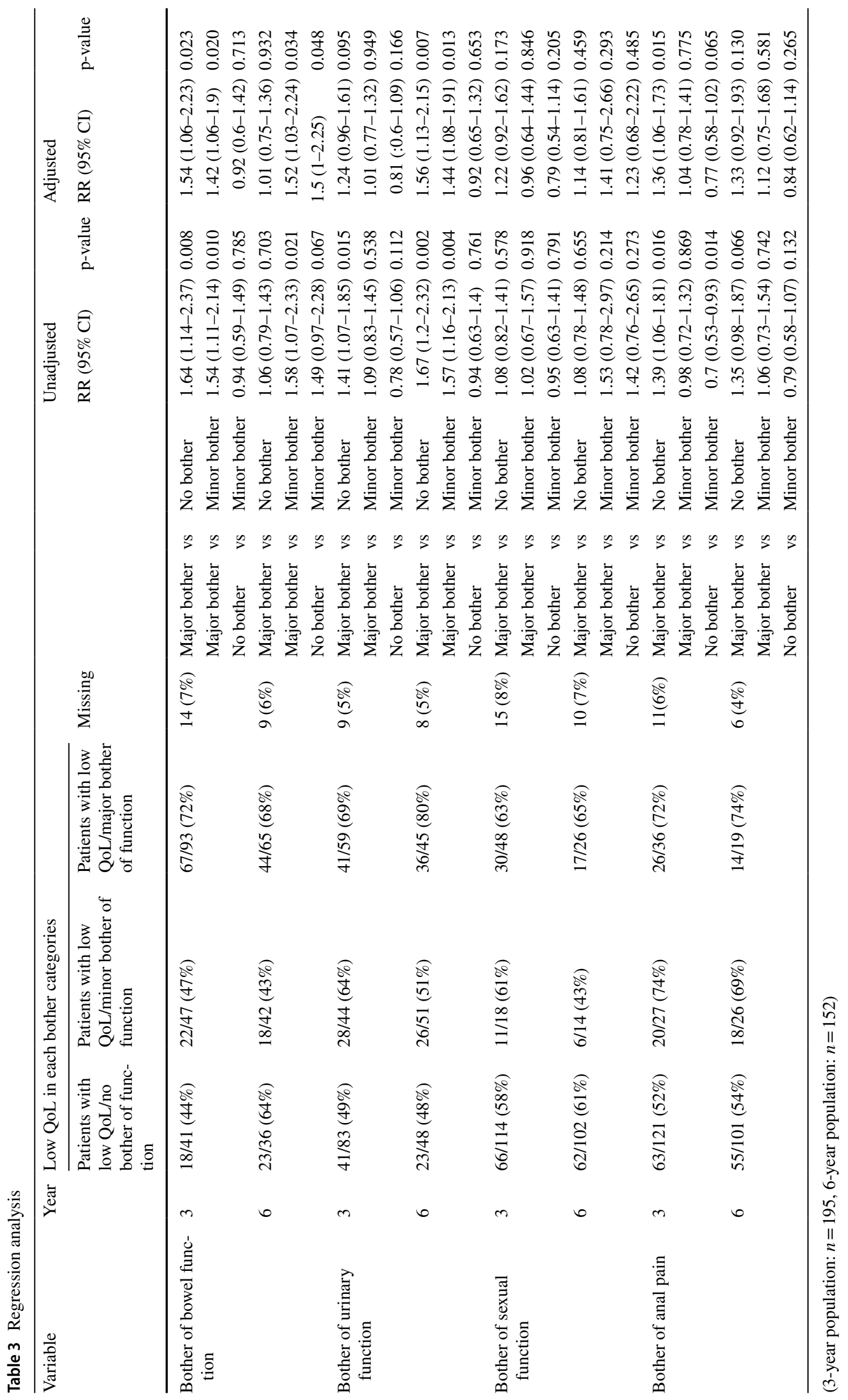


Fig. 3 Correlation between numbers of bothers There are no patients reporting 3 bothers of symptoms at the 6-year follow-up

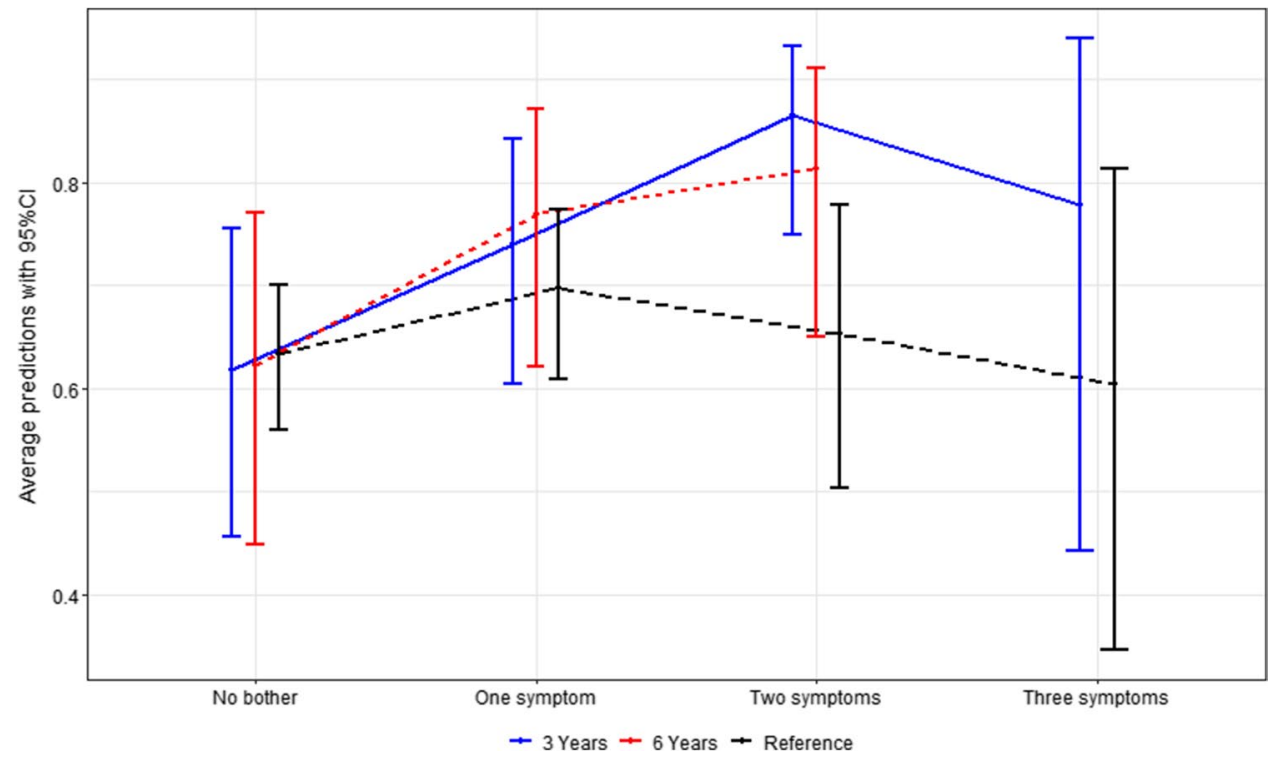

patients adjust over time to their functional symptoms resulting in less bother and no deterioration. This phenomenon is described in a conceptual framework called response shift theory [20]. Response shift is thought of as a positive adaptive process occurring over time. Patients report better outcomes over time, not because they are "objectively" doing better, but because they have adapted psychologically and match their new life circumstances in order to better cope with them. Response shifting is considered to involve a re-prioritization of values. The effects of this process could be seen as a potential source of bias, if one wished to quantify the long-term side effects of a given treatment. In QoL research, however, response shifting is considered to be fundamental to understand patient-reported and perceived QoL $[11,12]$. Taken together with the fact that bother remained over time, as did reduce QoL, it could be of value to offer follow-up after more than 3 years for patients with anal cancer.

Strengths with this study include the nationwide cohort, the relatively large number of patients included, the high response rate, and the longitudinal design with considerably longer follow-up than usually reported in studies on anal cancer survivorship. Another strength with in this study is the use of an anal cancer-specific questionnaire compared with earlier studies using more generic instruments. In further research, it would also be of great interest to use the EORTC QLQ-ANL27 [19].

One limitation is the lack of a baseline questionnaire, which would have facilitated detection of patient-related factors influencing QoL prior to treatment. Another limitation is that there are some differences between the ANCA cohort and the reference population, even though we have corrected for age there is a possibility that the older age in the ANCA cohort that renders more patients to be retired my affect overall QoL when comparing groups. It must also be considered that the patients that did not respond to the questionnaire but that were still alive were somewhat older and more co-morbid, which must be taken into account when extrapolating results.

Another limitation is the diverse treatment schedules applied, due to a lack of national guidelines and various treatment traditions at different centers in Sweden during the study period. A national treatment guideline, a national multidisciplinary conference, and centralization to four university hospitals were introduced in 2017. Whether this will have an impact on QoL remains to be studied.

\section{Conclusions}

Bother regarding bodily functions are of importance to QoL, and our study indicates that clinical follow-up should include routine questions on function as well as self-perceived bother in order to identify and treat symptoms and dysfunctions and possibly thereby improve QoL.

Author contribution All authors contributed to the study conception and design. Material preparation was performed by EA, $\mathrm{H}$ de la C, and EH. Data collection was performed by EA and EH. Analysis was performed by AA, DB, EA, and EH. The first draft of the manuscript was written by AA, and all authors commented on results and the manuscript. All authors approved the final manuscript.

Funding Open access funding provided by University of Gothenburg. The Swedish Cancer Society, Senior Clinical Investigator Award and CAN 2016/509 and 190333 Pj, The Swedish Research Council 201701103, The Agreement concerning research and education of doctors ALFGBG-716581 and The Healthcare Committee, Region Västra 
Götaland (Hälso- och sjukvårdsstyrelsen) VGFOUREG-855181 and VGRFOUREG-644421.

Data availability Data is stored by authors and may be available upon request.

Code availability N/A.

\section{Declarations}

Ethics approval This study was performed in line with the principles of the Declaration of Helsinki. The study was approved by the Regional Ethical Committee (EPN) in Gothenburg. (Dnr. 495-15). Permission to use the Sense of Coherence scale was obtained. The study was registered at Clinical Trials NCT02546973.

Consent to participate Informed consent was obtained from all individual participants included in the study.

\section{Consent for publication N/A.}

Conflict of interest The authors declare no competing interests.

Open Access This article is licensed under a Creative Commons Attribution 4.0 International License, which permits use, sharing, adaptation, distribution and reproduction in any medium or format, as long as you give appropriate credit to the original author(s) and the source, provide a link to the Creative Commons licence, and indicate if changes were made. The images or other third party material in this article are included in the article's Creative Commons licence, unless indicated otherwise in a credit line to the material. If material is not included in the article's Creative Commons licence and your intended use is not permitted by statutory regulation or exceeds the permitted use, you will need to obtain permission directly from the copyright holder. To view a copy of this licence, visit http://creativecommons.org/licenses/by/4.0/.

\section{References}

1. Adams E, Boulton MG, Horne A, Rose PW, Durrant L, Collingwood M, Oskrochi R, Davidson SE, Watson EK (2014) The effects of pelvic radiotherapy on cancer survivors: symptom profile, psychological morbidity and quality of life. Clin Oncol ( $R$ Coll Radiol) 26:10-17

2. Angenete E, Correa-Marinez A, Heath J, Gonzalez E, Wedin A, Prytz M, Asplund D, Haglind E (2012) Ostomy function after abdominoperineal resection--a clinical and patient evaluation. Int J Colorectal Dis 27:1267-1274

3. Antonovsky A (1993) The structure and properties of the sense of coherence scale. Soc Sci Med 36:725-733

4. Asplund D, Bisgaard T, Bock D, Burcharth J, Gonzalez E, Haglind E, Kolev Y, Matthiessen P, Rosander C, Rosenberg J, Smedh K, Sorensson MA, Angenete E (2017) Pretreatment quality of life in patients with rectal cancer is associated with intrusive thoughts and sense of coherence. Int J Colorectal Dis 32:1639-1647

5. Asplund D, Prytz M, Bock D, Haglind E, Angenete E (2015) Persistent perineal morbidity is common following abdominoperineal excision for rectal cancer. Int J Colorectal Dis 30:1563-1570

6. Bentzen AG, Balteskard L, Wanderas EH, Frykholm G, Wilsgaard T, Dahl O, Guren MG (2013) Impaired healthrelated quality of life after chemoradiotherapy for anal cancer: late effects in a national cohort of 128 survivors. Acta Oncol 52:736-744

7. Bock D, Angenete E, Gonzales E, Heath J, Haglind E (2018) Assessing health, quality of life and urogenital function in a sample of the Swedish general population: a cross-sectional study. BMJ Open 8:e021974

8. Glynne-Jones R, Northover JM, Cervantes A, Group EGW (2010) Anal cancer: ESMO Clinical Practice Guidelines for diagnosis, treatment and follow-up. Ann Oncol 21 Suppl 5: v87-92

9. Gore JL, Gollapudi K, Bergman J, Kwan L, Krupski TL, Litwin MS (2010) Correlates of bother following treatment for clinically localized prostate cancer. J Urol 184:1309-1315

10. Haglind E, Carlsson S, Stranne J, Wallerstedt A, Wilderang U, Thorsteinsdottir T, Lagerkvist M, Damber JE, Bjartell A, Hugosson J, Wiklund P, Steineck G, committee Ls (2015) Urinary incontinence and erectile dysfunction after robotic versus open radical prostatectomy: a prospective, controlled, nonrandomised trial. Eur Urol 68:216-225

11. Howard JS, Mattacola CG, Howell DM, Lattermann C (2011) Response shift theory: an application for health-related quality of life in rehabilitation research and practice. J Allied Health 40:31-38

12. Ilie G, Bradfield J, Moodie L, Lawen T, Ilie A, Lawen Z, Blackman C, Gainer R, Rutledge RDH (2019) The role of responseshift in studies assessing quality of life outcomes among cancer patients: a systematic review. Front Oncol 9:783

13. James RD, Glynne-Jones R, Meadows HM, Cunningham D, Myint AS, Saunders MP, Maughan T, McDonald A, Essapen S, Leslie M, Falk S, Wilson C, Gollins S, Begum R, Ledermann J, Kadalayil L, Sebag-Montefiore D (2013) Mitomycin or cisplatin chemoradiation with or without maintenance chemotherapy for treatment of squamous-cell carcinoma of the anus (ACT II): a randomised, phase 3, open-label, $2 \times 2$ factorial trial. Lancet Oncol 14:516-524

14. Knowles G, Haigh R, McLean C, Phillips H (2015) Late effects and quality of life after chemo-radiation for the treatment of anal cancer. Eur J Oncol Nurs 19:479-485

15. Leon O, Guren M, Hagberg O, Glimelius B, Dahl O, Havsteen H, Naucler G, Svensson C, Tveit KM, Jakobsen A, Pfeiffer P, Wanderas E, Ekman T, Lindh B, Balteskard L, Frykholm G, Johnsson A (2014) Anal carcinoma - survival and recurrence in a large cohort of patients treated according to nordic guidelines. Radiother Oncol 113:352-358

16. Pan YB, Maeda Y, Wilson A, Glynne-Jones R, Vaizey CJ (2018) Late gastrointestinal toxicity after radiotherapy for anal cancer: a systematic literature review. Acta Oncol 57:1427-1437

17. Skoogh J, Ylitalo N, Larsson Omerov P, Hauksdottir A, Nyberg U, Wilderang U, Johansson B, Gatz M, Steineck G, Swedish-Norwegian Testicular Cancer G (2010) 'A no means no'--measuring depression using a single-item question versus Hospital Anxiety and Depression Scale (HADS-D). Ann Oncol 21:1905-1909

18. Sodergren SC, Johnson CD, Gilbert A, Tomaszewski KA, Chu W, Chung HT, Dennis K, Desideri I, Glynne-Jones R, Grønlie Guren M, Kardamakis D, Nugent K, Schmidt H, Sebag-Montefiore D, Vassiliou V (2018) Phase I-III development of the EORTC QLQANL27, a health-related quality of life questionnaire for anal cancer. Radiother Oncol 126:222-228

19. Sodergren SC, Vassiliou V, Dennis K, Tomaszewski KA, Gilbert A, Glynne-Jones R, Nugent K, Sebag-Montefiore D, Johnson CD, Group EQoL (2015) Systematic review of the quality of life issues associated with anal cancer and its treatment with radiochemotherapy. Support Care Cancer 23:3613-3623

20. Sprangers MAG, Schwartz CE (1999) Integrating response shift into health-related quality of life research: a theoretical model. Soc Sci Med 48:1507-1515 
21. Steineck G, Helgesen F, Adolfsson J, Dickman PW, Johansson JE, Norlen BJ, Holmberg L, Scandinavian Prostatic Cancer Group Study N (2002) Quality of life after radical prostatectomy or watchful waiting. N Engl J Med 347:790-796

22. Sterner A, Derwinger K, Staff C, Nilsson H, Angenete E (2019) Quality of life in patients treated for anal carcinoma-a systematic literature review. Int J Colorectal Dis 34:1517-1528

23. Stroup WW (2013) Generalized linear mixed models: modern concepts, methods and applications. CRC Press, Boca Rato, Florida

24. Sunesen KG, Norgaard M, Lundby L, Havsteen H, Buntzen S, Thorlacius-Ussing O, Laurberg S (2015) Long-term anorectal, urinary and sexual dysfunction causing distress after radiotherapy for anal cancer: a Danish multicentre cross-sectional questionnaire study. Colorectal Dis 17: O230-239

25. Team RDC (2008) R: A language and environment for statistical computing. R Foundation for Statistical Computing. In: Editor (ed)^(eds) Book R: A language and environment for statistical computing. R Foundation for Statistical Computing, City.
26. Wallerstedt A, Nyberg T, Carlsson S, Thorsteinsdottir T, Stranne J, Tyritzis SI, Stinesen Kollberg K, Hugosson J, Bjartell A, Wilderang U, Wiklund P, Steineck G, Haglind E (2019) Quality of life after open radical prostatectomy compared with robot-assisted radical prostatectomy. Eur Urol Focus 5:389-398

27. Walming S, Asplund D, Bock D, Gonzalez E, Rosenberg J, Smedh $\mathrm{K}$, Angenete E (2020) Quality of life in patients with resectable rectal cancer during the first 24 months following diagnosis. Colorectal Dis

28. Yerramilli D, Drapek L, Nipp RD, Horick N, Moran SMC, Noe B, D'Arpino SM, Mitra D, Hong TS, Ryan DP, Dizon DS, Wo J (2019) Sexual function, quality of life, and mood after radiation therapy in patients with anal cancer. J Gastrointest Cancer

29. Zou G (2004) A modified Poisson regression approach to prospective studies with binary data. Am J Epidemiol 159:702-706

Publisher's note Springer Nature remains neutral with regard to jurisdictional claims in published maps and institutional affiliations. 